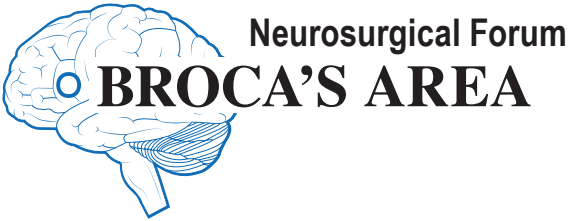

\section{Football fatalities: the first-impact syndrome}

\author{
Julian E. Bailes, MD,1,2 Vimal Patel, PhD, ${ }^{1,2}$ \\ Hamad Farhat, MD, ${ }^{3}$ Brian Sindelar, MD, ${ }^{1,4}$ and \\ James Stone, MD ${ }^{1,5}$ \\ 1'Department of Neurosurgery, NorthShore University HealthSystem, \\ Evanston, Illinois \\ 2University of Chicago, Pritzker School of Medicine, Chicago, Illinois \\ ${ }^{3}$ Department of Neurosurgery, Advocate Christ Medical Center, \\ Oak Lawn, Illinois \\ ${ }^{4}$ Department of Neurosurgery, University of Florida, Gainesville, Florida \\ ${ }^{5}$ Department of Neurosurgery, University of Illinois at Chicago, Illinois
}

$\mathrm{A}$ CUTE death resulting from head trauma is a rare but catastrophic and unfortunate occurrence in contact sports, particularly American football. Although the incidence of acute death is lower now than it was decades before, it nonetheless continues to occur and is associated with several important characteristics. Of concern is that there is no responsible governmental or central reporting agency tracking these events; however, available statistics indicate that during the last 20 years, an average of 4 fatalities due to acute brain trauma occur annually, almost all in high school football players. ${ }^{21-27}$ Despite the warnings and notoriety of "second-impact syndrome" (SIS), this entity is a poorly understood, but often ascribed, phenomenon and one that has often led to plaintiffs' attorneys and their experts accusing medical personnel, athletic trainers, and coaches of ignoring or missing the warning and prior impacts, which subsequently are blamed for the second, or fatal, blow. Our experience, however, indicates that rather than attributing head injury to the poorly documented and ill-defined SIS, it is quite common and understandable that the fatal head blow is often in reality the first, horrific one. Thus, the majority of these occurrences are most appropriately termed "firstimpact syndrome."

Analyses of online news resources in the calendar year
2015 and up until the time of submission of this article were used to obtain details of a fatal injury, how it was managed, as well as the cause of death. Case 1 was a patient at our institution, and the details of Cases 2-5 were derived from and limited to the published events of the injury, and therefore are not complete. We also used online published annually reported data from the National Center for Catastrophic Sports Injury Research (NCCSIR), which also used media reporting to document injures. ${ }^{21-27}$ A direct football fatality is described as one that results directly from participation in the fundamental skills of football, such as a brain injury or spinal fracture. In contrast, indirect football fatalities are those that are caused by systemic failure as a result of exertion while participating in a football activity (such as heat stroke or cardiac defect) or by a complication that was secondary to a nonfatal injury (e.g., infection). In this paper we review the fatalities specifically caused by cranial injuries directly related to football from 2008 to 2015 and describe our experience in this regard, offering pathophysiological explanations for the phenomenon.

\section{Case Report (Direct Intracranial Traumatic Injury) Case 1}

A 17-year-old healthy boy was hit on the last play of the game when returning a kick for his high school football team. He walked off the field and shortly thereafter, vomited, collapsed, and became pulseless. Cardiopulmonary resuscitation (CPR) was initiated with successful return of circulation. During transportation to the local hospital, the patient's course was complicated with an ictal event and airway compromise requiring emergency intubation. Upon arrival to the emergency room (approximately 7:15 PM), the initial neurological examination included fixed and dilated pupils, absent gag/corneal/oculocephalic reflexes, and nonlocalizing movements to pain. Measures to reduce intracranial pressure (ICP; i.e., mannitol and hypertonic saline) and for seizure prophylaxis were initiated. A head CT scan revealed cerebral edema and a right subdural hematoma with midline shift (Fig. 1). He was admitted to the neuro- 


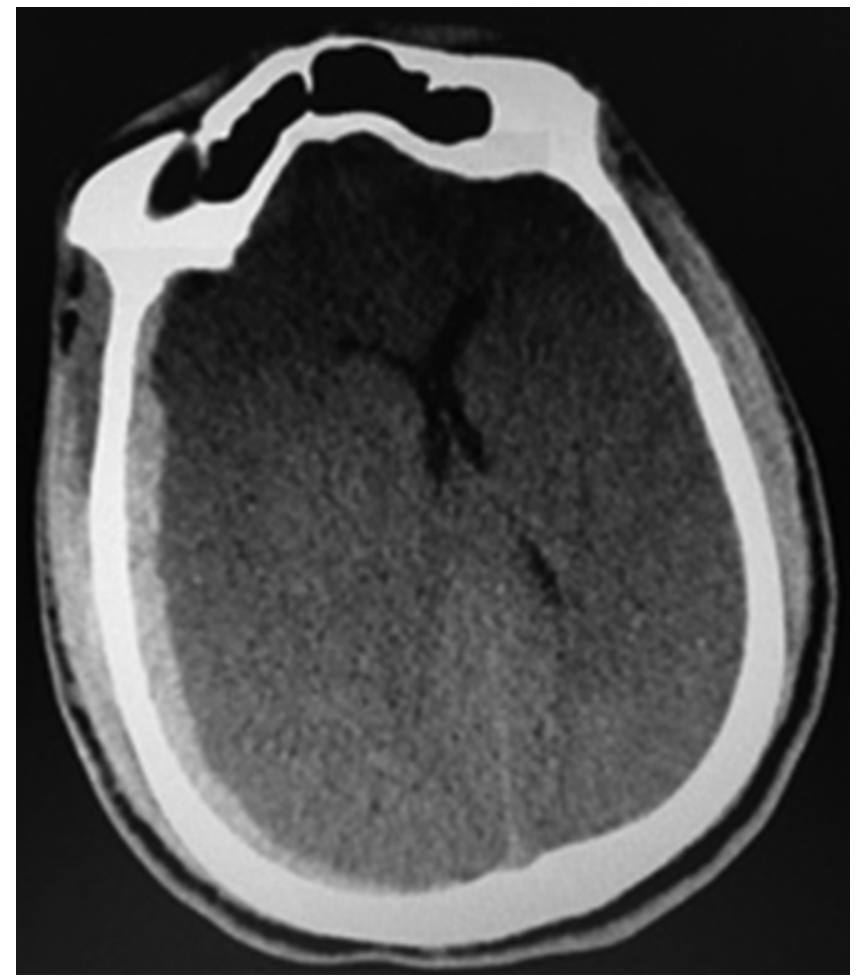

FIG. 1. Case 1. Axial CT scan of 17-year-old boy with a large right subdural hematoma with midline shift due to a major blunt force head impact in football.

surgical intensive care unit. At 12 midnight, he developed hypertension and tachycardia that was nonresponsive to medical therapy. At 1 AM, the patient became hypotensive with subsequent pulseless electrical activity. After repeated rounds of CPR on the patient, he was declared dead. The medical examiner reported the cause of death as "blunt force head injuries due to a football accident."

\section{Other Direct Football Fatalities in 2015 (Cranial Injuries Only)}

Case 2

A 17-year-old male senior football player, following a play as a defensive back, stepped off the field and appeared dazed. As athletic trainers asked him questions from the concussion protocol, the patient became unresponsive. Emergency personnel were notified, and the patient was transferred to the local medical center. Neurological examination details are limited, but due to his unresponsive state an emergency craniectomy was performed. He was pronounced dead 3 days later. The autopsy report indicated the cause of death as "subdural hematoma with associated cerebral edema." Of note, the patient was reportedly removed from a game with a concussion 1 month prior to this injury, went through a concussion protocol, and was cleared to play 2 weeks later.

\section{Case 3}

Following a short-yardage rushing touchdown, a 17-yearold boy was injured during the subsequent play (kickoff return) in the fourth quarter. He collapsed at midfield and then proceeded unassisted to the team's bench. The player was confronted by his father, but was unable to respond to questioning. Awaiting medical personnel, the patient lay down next to the bench and began to experience emesis. Emergency personnel arrived to find an unresponsive patient and intubation was attempted but was unsuccessful. After roughly 45 minutes, he was taken to the local hospital where an advanced airway was placed. He was subsequently transported to a regional hospital and was diagnosed with a "brain bleed" and surgery was performed. He was placed in a medically induced coma but his condition worsened because of a "lack of oxygen in his blood," and he died 8 days later. Of important note, he had suffered a concussion with a "brain bleed" 2 years prior. The patient returned to play 1 year following that injury.

\section{Case 4}

A 17-year-old boy told his teammates during a huddle that he felt dizzy. Shortly thereafter, he collapsed on the sidelines following an uneventful kickoff return. Reports are that he "suffered a seizure and attempts were made to keep him ventilated." He was transported by helicopter to a hospital where he was later pronounced dead. The autopsy report indicated the cause of death as "blunt impact to the head" and "anoxic encephalopathy following resuscitation from cardiac arrest from unspecified blunt impact."

\section{Case 5}

A 17-year-old male linebacker was tackled as he reached the end zone for a 2-point conversion in the third quarter. After being tackled, he ran to the sidelines and subsequently collapsed. He was airlifted to a medical center where he was placed on artificial life support and subsequently pronounced dead 5 days later. The cause of death was noted as "head trauma."

\section{Case Analysis of Direct Football Fatalities in 2008-2015 (Cranial Injuries Only)}

From 2008 to 2015 there were a total of 42 direct football fatalities. ${ }^{21-27}$ The vast majority of these injuries occurred during high school football, which in 2014 had more than 1.1 million participants. Of these 42 deaths, 29 were due to cranial injuries (Table 1). ${ }^{21-27}$

The major cause of death in football remains brain injury with hemorrhage and identified intracranial hemorrhage $(15 / 42,36 \%)$, followed by head trauma $(11 / 42,26 \%)$ and vertebral fracture $(5 / 42,12 \%) .{ }^{21-27}$ In the NCCSIR reports, in one case death was attributed to SIS (in 2008) in which the player was not cleared from a previous concussion, and there was second case that was a "possible" case of SIS in an 11-year-old who had suffered a concussion in a game 2 days prior and "hit his head" while playing. Two players had experienced a previous intracranial hemorrhage-one 2 years prior and the other 1 month prior-but were cleared to play. The majority of fatal cranial injuries occurred in games $(22 / 29,76 \%)$, followed by practice $(6 / 29,21 \%$; Table 1). The majority of fatal injuries occurred while the player was making a tackle $(9 / 29,31 \%)$, followed by a kick or punt return $(5 / 29,17 \%$; Table 1$)$. In many cases the play 
TABLE 1. Details of the 29 direct fatalities due to cranial injures in football for the period $2008-2015$

\begin{tabular}{|c|c|c|c|c|c|c|c|}
\hline $\begin{array}{c}\text { Case } \\
\text { No. }\end{array}$ & Yr & Age (yrs) & Level & Game/Practice/Scrimmage & Player Position & Injury Play & Cause of Death \\
\hline 1 & 2015 & 17 & HS & Game & NA & Kick return & Hemorrhage \\
\hline 2 & 2015 & 17 & HS & Game & DB & Making tackle & Head trauma \\
\hline 3 & 2015 & 17 & HS & Game & NA & Kick return & Hemorrhage \\
\hline 4 & 2015 & 17 & HS & Game & NA & Kick return & Head trauma \\
\hline 5 & 2015 & 17 & HS & Game & LB & Being tackled & Head trauma \\
\hline 6 & 2014 & 17 & HS & Game & Unknown & Making tackle & Hemorrhage \\
\hline 7 & 2014 & 16 & HS & Game & LB & Making tackle & Head trauma \\
\hline 8 & 2014 & Junior & HS & Game & NA & Kick return & Head trauma \\
\hline 9 & 2014 & 18 & HS & Game & LB & Unknown & Hemorrhage \\
\hline 10 & 2014 & 19 & College & Practice & RB & Unknown & Head trauma \\
\hline 11 & 2013 & 16 & HS & Scrimmage & Unknown & Unknown & Hemorrhage \\
\hline 12 & 2013 & 17 & HS & Game & $\mathrm{RB}$ & Being tackled & Head trauma \\
\hline 13 & 2013 & 17 & HS & Game & WR & Unknown & Hemorrhage \\
\hline 14 & 2013 & 17 & HS & Game & WR & Unknown & Head trauma \\
\hline 15 & 2013 & 17 & HS & Game & RB & Being tackled & Head trauma \\
\hline 16 & 2011 & 16 & HS & Game & DT & Helmet-to-helmet hit & Hemorrhage \\
\hline 17 & 2011 & 17 & HS & Practice & Unknown & Making tackle & Aneurysm \\
\hline 18 & 2011 & Senior & College & Practice & RB & Unknown & Hemorrhage \\
\hline 19 & 2010 & 17 & HS & Game & Unknown & Unknown & Hemorrhage \\
\hline 20 & 2010 & 11 & Sandlot & Game & Unknown & Hit head accidently & Possible SIS \\
\hline 21 & 2010 & 21 & College & Game & Unknown & Making tackle & Hemorrhage \\
\hline 22 & 2010 & 18 & College & Practice & $\mathrm{DL}$ & Blocked & Head trauma \\
\hline 23 & 2009 & 17 & HS & Game & DB & Making tackle & Hemorrhage \\
\hline 24 & 2009 & 10 & Sandlot & Practice & NA & Kick return & Hemorrhage \\
\hline 25 & 2008 & 17 & $\mathrm{HS}$ & Practice & Unknown & Making tackle & Hemorrhage \\
\hline 26 & 2008 & 15 & HS & Game & LB & Helmet-to-helmet hit & Hemorrhage \\
\hline 27 & 2008 & Sophomore & HS & Game & DB & Making tackle & Head trauma \\
\hline 28 & 2008 & 16 & HS & Game & RB & Being tackled & SIS \\
\hline 29 & 2008 & 16 & HS & Game & LB & Making tackle & Hemorrhage \\
\hline
\end{tabular}

$\mathrm{DB}=$ defensive back; $\mathrm{DL}$ = defensive line; $\mathrm{DT}$ = defensive tackle; $\mathrm{HS}$ = high school; $\mathrm{LB}$ = linebacker; $\mathrm{NA}$ = not applicable; $\mathrm{RB}$ = running back; $\mathrm{WR}=$ wide receiver

Compilation of data from 2008-2014 NCCSIR reports (online media reporting) and 2015 data from online media reporting.

$(7 / 29,24 \%)$ or the player position $(7 / 29,24 \%)$ during the injury was unknown because details of each case listed in these reports are minimal due to use of online media and do not provide complete information as to the origin of the fatal injury. However, this is the best available current information in the absence of a responsible governmental or central reporting agency tracking these events.

\section{Fatal Football Brain Injuries}

The National Collegiate Athletic Association (NCAA) was formed in 1905 when President Theodore Roosevelt assembled the presidents of the major football-playing universities and instructed them to reform the sport, as there were 19 deaths in college football that year. ${ }^{20}$ Due to the lack of a central or governmental reporting agency regarding the incidence of major or lethal brain injury in football, we are left with surveying lay press reports, while our most accurate information is gathered by the NCC-
SIR. Their data show that during the last 3 decades there have been an average of 4 fatalities annually in American football due to intracranial injury. ${ }^{21-27}$ Prior injury trends (before 2008) showed even more deaths in football, which presumably decreased due to a series of rule changes in 1976, primarily in an effort to limit or eliminate spearing, i.e., making a tackle or initial contact with the top or crown of the helmet. ${ }^{7}$ Since then, the number of injuries has been relatively stable, but unfortunately no reduction in brain injury fatalities has been noted. Coincident with this period, no significant improvements in safety equipment (particularly helmets) or newer strategies to mitigate such injuries have been adopted.

Analyzing the specific cases of fatal football cranial injuries in 2015 (Table 1) brings several points to light. All 5 deaths in 2015 were in the adolescent age group and during high school football games (not during practice). Three of the 5 fatal injuries were on "extra plays," either on a 
kick-off/punt return or 2-point conversion. This point supports the ongoing conversation about removing these plays from football. In one of the cases, the individual suffered a concussion 1 month prior, went through the concussion protocol, and was cleared to play 2 weeks later. Another case was reported to have suffered a "brain bleed" 2 years prior. These 2 deaths raise the possibility of an individual predisposition to single catastrophic head impact. Lastly, 3 other players did not have any documented history of a recent/remote concussion.

\section{Second-Impact Syndrome}

Currently SIS literature does not provide evidence to support a unique case definition for SIS, based on a format consistent with the WHO-derived ICD-10 clinical case definitions. ${ }^{11}$ Between 1980 and 1993 the NCCSIR identified 35 probable SIS cases among American football players. ${ }^{5,7}$ Others have reported that the number of reported cases of SIS based on stricter criteria is $17 .{ }^{18,19}$ However, this syndrome and its incidence have been called into question by the lack of similar reports from Australian football, despite the high participation rate and a concussion rate about 8 times greater than that of American football. ${ }^{17}$ The European literature also similarly lacks support for SIS. ${ }^{2,19}$ In addition, there is a paucity of SIS cases in boxing, a sport with repetitive head impacts, even within each bout. There is no doubt that brain swelling may occur in response to a head injury; rather, it is the issue of whether a previous concussive injury is a risk factor for this condition that is disputed. ${ }^{18}$ The cases of proposed SIS harboring a subdural hematoma would appear more likely to have been produced by a recent impact of a sufficient magnitude of force to produce both the acute subdural hematoma and associated cerebral edema. ${ }^{6,18}$ The rarity of SIS or diffuse cerebral swelling after acute trauma could also be due to an underling genetic susceptibility rather than a response to impact alone. ${ }^{14,18}$ This notable rarity has also limited detailed investigation to identify the exact cause. In a report by Cantu et al., $71 \%$ of the type of brain injuries we describe in high school football players had a previous concussion in the same season, and 39\% were playing with residual symptoms. ${ }^{3,6,8}$ This had led to the assumption that most patients with such injuries must have had an earlier concussion.

While SIS has been described with variable documentation and number of prior impacts, the contention that the continually symptomatic player had another, subsequent, and often less than major cranial impact to cause his deterioration, is not substantiated in the majority of our cases. Rather, we stress that there is the distinct probability that a single, massive cranial impact is sufficient to cause an instantaneous change in cerebrovascular dynamics. ${ }^{12}$ It is also possible that those hits, which are significant enough to cause an immediate and irreversible syndrome of cerebral vasodilation and elevated ICP, cause conditions refractory to medical and surgical treatment, and which can proceed inexorably to cause fatal brain ischemia and herniation syndrome. The brain's ability to move inside the skull explains why and how there is injury with highvelocity impacts, despite the presence of the football helmet. Also, through the years the style of play has evolved so that some players have a propensity to strike another with the helmeted cranium, leading to the potential for axonal stretching and tearing (concussion); or if of sufficient severity, there is the possibility of causing significant brain movement leading to hemispheric injury and/or tearing of bridging veins and subdural hematoma formation, and occasionally death. ${ }^{32,35}$

\section{Mechanism of a Catastrophic Single Head Impact}

As our analysis emphasizes, there is the unusual but predictable occurrence of acute head injury fatalities in football, which ordinarily transpire following a single, high-impact cranial hit, often on plays in which the players are running at high speed such as on a punt or kickoff return. These high-velocity cranial impacts then result in a cascade of events typical of acute, severe traumatic brain injury. The primary and secondary injuries can rapidly result in cerebral vasomotor instability, vasodilation, and resultant intracranial hypertension. This was originally described by Langfitt et al. in the 1960s, with the characteristic finding of hemispheric swelling, which today is noted on initial CT scans. ${ }^{15}$ Langfitt's laboratory studies showed that following a severe blow to the head, a progressive rise in ICP occurred, and if the arterial blood pressure was exceeded by the ICP, shock and death rapidly ensued.

Most often the pathological explanation for death of an athlete who has experienced head trauma is a large subdural hematoma. However, while the presence of subdural hemorrhage is sometimes noted, it may often be a small clot and represents an epiphenomenon. Experimental evidence indicates that a severe cranial impact is capable of inducing severe, immediate, and often irreversible vasomotor instability through cerebral vasodilation, which progresses to deleterious and often fatal rises in ICP. As ICP rises, there is an attempted compensatory vasodilation that leads to intense cerebrovascular congestion, ultimately cycling to further and often lethal intracranial hypertension. We stress that there is no requisite prior or initial hit to set the stage for this torrent of cellular events, as has been demonstrated repeatedly for those who suffer from high-velocity vehicle collisions or falls. ${ }^{13}$

Langfitt et al. found an immediate rise in ICP of 15$150 \mathrm{~mm} \mathrm{Hg}$ following severe blunt occipital injuries in cats, ascribing it to a traumatically induced paretic, cerebrovascular dilation with resultant rise in cerebral blood volume. ${ }^{15}$ Saunders et al. observed immediate, transient rises in ICP in all animals that sustained a mild epidural trauma, supporting the contention that posttraumatic transient ICP elevations are mediated by neurovascular mechanisms. ${ }^{33}$ They opined that vasoparesis would result in cerebral vasodilation with subsequent increase in blood volume and thus, elevated ICP. ${ }^{33}$ In a classic study titled "Diffuse cerebral swelling following head injuries in children: the syndrome of 'malignant brain edema', Bruce et al. described the syndrome of malignant brain edema. ${ }^{4}$ The most common finding in 63 children with this pattern was bilateral, diffuse swelling on CT. Cerebral blood flow and CT density studies suggested this swelling was due to increased cerebral blood volume or "cerebral hyperemia" and not edematous fluid. ${ }^{4}$ Of the 63 children, 14 had a Glasgow Coma Scale (GCS) score greater then 8; 
all experienced a complete recovery, and follow-up CT scans were normal. Forty-nine children had a GCS score equal to or lower than 8 , of whom 15 experienced a lucid period following the initial concussion. The remaining 34 were immediately and continuously unconscious. ${ }^{4}$ This latter group had a higher incidence of second lesions on $\mathrm{CT}$, about half demonstrated high ICP, 5 died, and the rest remained in a coma for weeks to months. ${ }^{4}$ The difference between those with and without a lucid period was believed to be related to the degree of primary diffuse impact injury to the white matter. ${ }^{4}$ Thus, it would appear that children, including high school-aged youths, are vulnerable to hyperemic cerebral swelling after sufficient impact to the head, and one need not conjecture that a previous recent concussion must have been present. ${ }^{28-30}$

Traumatic subdural hemorrhage is an entity often responsible for deaths in boxing and originates from 3 anatomical sites: a hemorrhagic contusion or intraparenchymal hematoma that ruptures through the arachnoid layer, a laceration of a cortical artery or vein, or a rupture of 1 or more bridging veins that course in the subdural space from the cortex, typically to the superior sagittal sinus (SSS). ${ }^{17}$ In blunt head trauma, as observed in sports such as football, the last mechanism usually occurs. These bridging veins originate predominantly from the superolateral surface of the frontal lobe, or parietal lobes, and run anteriorly toward the SSS with the insertion angle varying from $10^{\circ}$ to $85^{\circ}$. Upon impact with variable amounts of acceleration/deceleration and rotational forces, the brain lags behind the cranium (also termed "brain slosh" or "brain decoupling") and longitudinal strain results in tearing of bridging veins. ${ }^{34,36}$ Whereas side impacts are believed to result in contusions or subarachnoid hemorrhage, frontal or occipital impacts have been shown to cause most cases of subdural hemorrhages due to the position of the bridging veins and the direction of these force vectors. ${ }^{31}$ Lee and Haut have estimated that cranial rotational acceleration contributes 2.5 times as much force to the deformation of forward-draining bridging veins as compared with translational acceleration. ${ }^{16}$ Depreitere et al. studied 10 cadavers using occipital impacts producing head rotation in the sagittal plane with varying rotational acceleration magnitudes and pulse durations, finding a tolerance of approximately $10,000 \mathrm{rad} / \mathrm{sec}^{2}$ for pulse durations shorter than 10 milliseconds for bridging vein rupture. ${ }^{9}$ Through detailed review, it appears the biomechanical threshold of rotational acceleration required for bridging vein rupture and resultant subdural hemorrhage formation at collision durations noted in American football approximates 5000 $\mathrm{rad} / \mathrm{sec}^{2}$, which are not seen infrequently in high school football games. ${ }^{10}$

\section{Prospects for Football}

The future of the sport of American football resides in its ability to continue the "second reformation," which began in 2009 led by changes in all levels of play, from the National Football League and NCAA and extending all the way down to youth football. The Pop Warner Football League in 2012 became the first level of play to formally reduce head contact in practice, by eliminating head-tohead contact drills. Subsequent studies of league play with an adherence to these rules and implementation of "HeadsUp" football coaching education showed a marked reduction in cranial impacts, to approximately 100 annually, and current concussion rates are estimated at $1 \%$ of players per season. ${ }^{37}$ In 2016, Pop Warner football became the first level of play to eliminate the kickoff, initially for the youngest age groups. ${ }^{1}$ The enforcement of rules prohibiting the initiation of contact head-first and reducing gratuitous head contact are important to reduce unnecessary cranial impacts and prevent catastrophic brain injury. The continued inclusion of high-speed plays such as punts and kickoffs may need to be reconsidered. Helmet technology is unlikely to substantially further contribute to a material reduction in the incidence of fatal brain injury (Fig. 1), as helmets are not able to prevent brain decoupling inside the skull, i.e., the brain slosh effect. ${ }^{34,36}$ Newer and emerging efforts to address brain slosh may be beneficial to limit major brain excursions, which may lead to serious and fatal hemispheric edema and subdural hemorrhage formation. It is important for all involved in the treatment of youth and high school football players after head injury to be aware of the potential for traumatically induced neurological injury and deterioration, and have the appropriate personnel, emergency services, equipment, and facilities to manage these patients in a timely fashion.

In summary, there is a small but quite consistent incidence of catastrophic and fatal brain injury in high school football. The typical course follows a major cranial impact and is the rapid onset of cerebral swelling, typically over an interval of several minutes. The impact is associated with cerebral hyperemia, suggesting the cerebral vasculature of the adolescent brain is prone to vasodilation and/or pooling of blood within the parenchyma, venous system, or extracellular spaces. A variable-sized acute subdural hematoma may also be present. We believe that this response to blunt impact is such that one does not have to have suffered a prerequisite, earlier, or unrecognized cerebral concussion. No youth or high school player should be allowed to play if still suffering any effects of an earlier concussion. This focused survey leads us to recommend that a student football player who has suffered any prior significant intracranial hemorrhage found on neuroimaging be considered prohibited from subsequently partaking in any contact or collision sport. Furthermore, particularly for the growth of high school football, league administration should consider whether continued use of high-velocity plays such as punt returns and kickoffs will be in the sport's best interest going forward.

\section{References}

1. Belson K: Pop Warner bans kickoffs in hopes of protecting its youngest players. New York Times. May 12, 2016. (http:// www.nytimes.com/2016/05/13/sports/football/pop-warnerbans-kickoffs-concussions-nfl.html) [Accessed August 24, 2016]

2. Bey T, Ostick B: Second impact syndrome. West J Emerg Med 10:6-10, 2009

3. Boden BP, Tacchetti RL, Cantu RC, Knowles SB, Mueller FO: Catastrophic head injuries in high school and college football players. Am J Sports Med 35:1075-1081, 2007

4. Bruce DA, Alavi A, Bilaniuk L, Dolinskas C, Obrist W, Uzzell B: Diffuse cerebral swelling following head injuries 
in children: the syndrome of "malignant brain edema". J Neurosurg 54:170-178, 1981

5. Cantu RC: Second-impact syndrome. Clin Sports Med 17:37-44, 1998

6. Cantu RC, Gean AD: Second-impact syndrome and a small subdural hematoma: an uncommon catastrophic result of repetitive head injury with a characteristic imaging appearance. J Neurotrauma 27:1557-1564, 2010

7. Cantu RC, Mueller FO: Brain injury-related fatalities in American football, 1945-1999. Neurosurgery 52:846-853, 2003

8. Cifu DX, Drake DF, Steinmetz BD: Repetitive head injury syndrome. Medscape. March 27, 2014. (http://emedicine. medscape.com/article/92189-overview) [Accessed August 24, 2016]

9. Depreitere B, Van Lierde C, Sloten JV, Van Audekercke R, Van der Perre G, Plets C, et al: Mechanics of acute subdural hematomas resulting from bridging vein rupture. J Neurosurg 104:950-956, 2006

10. Forbes JA, Zuckerman S, Abla AA, Mocco J, Bode K, Eads $\mathrm{T}$ : Biomechanics of subdural hemorrhage in American football: review of the literature in response to rise in incidence. Childs Nerv Syst 30:197-203, 2014

11. Hebert O, Schlueter K, Hornsby M, Van Gorder S, Snodgrass S, Cook C: The diagnostic credibility of second impact syndrome: A systematic literature review. J Sci Med Sport [epub ahead of print], 2016

12. Jünger EC, Newell DW, Grant GA, Avellino AM, Ghatan S, Douville CM, et al: Cerebral autoregulation following minor head injury. J Neurosurg 86:425-432, 1997

13. Kobrine AI, Timmins E, Rajjoub RK, Rizzoli HV, Davis DO: Demonstration of massive traumatic brain swelling within 20 minutes after injury. Case report. J Neurosurg 46:256-258, 1977

14. Kors EE, Terwindt GM, Vermeulen FL, Fitzsimons RB, Jardine PE, Heywood P, et al: Delayed cerebral edema and fatal coma after minor head trauma: role of the CACNA1A calcium channel subunit gene and relationship with familial hemiplegic migraine. Ann Neurol 49:753-760, 2001

15. Langfitt TW, Tannanbaum HM, Kassell NF: The etiology of acute brain swelling following experimental head injury. $\mathbf{J}$ Neurosurg 24:47-56, 1966

16. Lee MC, Haut RC: Insensitivity of tensile failure properties of human bridging veins to strain rate: implications in biomechanics of subdural hematoma. J Biomech 22:537542,1989

17. Maxeiner H: Detection of ruptured cerebral bridging veins at autopsy. Forensic Sci Int 89:103-110, 1997

18. McCrory P, Davis G, Makdissi M: Second impact syndrome or cerebral swelling after sporting head injury. Curr Sports Med Rep 11:21-23, 2012

19. McCrory PR, Berkovic SF: Second impact syndrome. Neurology 50:677-683, 1998

20. McQuillen JB, McQuillen EN, Morrow P: Trauma, sport, and malignant cerebral edema. Am J Forensic Med Pathol 9:12-15, 1988

21. National Center for Catastrophic Sport Injury Research: Annual Survey of Football Injury Research, 1931-2008. (http://nccsir.unc.edu/files/2014/05/FootballAnnual.pdf) [Accessed August 24, 2016]

22. National Center for Catastrophic Sport Injury Research:
Annual Survey of Football Injury Research, 1931-2009. (http://nccsir.unc.edu/files/2014/05/2009AnnualFootball.pdf) [Accessed August 24, 2016]

23. National Center for Catastrophic Sport Injury Research: Annual Survey of Football Injury Research, 1931-2010. (http://nccsir.unc.edu/files/2014/05/2010FBAnnual.pdf) [Accessed August 24, 2016]

24. National Center for Catastrophic Sport Injury Research: Annual Survey of Football Injury Research, 1931-2011. (http://nccsir.unc.edu/files/2014/05/2011FBAnnual.pdf) [Accessed August 24, 2016]

25. National Center for Catastrophic Sport Injury Research: Annual Survey of Football Injury Research, 1931-2012. (http://nccsir.unc.edu/files/2014/05/2012FBInj.pdf) [Accessed August 24, 2016]

26. National Center for Catastrophic Sport Injury Research: Annual Survey of Football Injury Research, 1931-2013. (https://nccsir.unc.edu/files/2013/10/Annual-Football-2013Fatalities-Final.pdf) [Accessed August 24, 2016]

27. National Center for Catastrophic Sport Injury Research: Annual Survey of Football Injury Research, 1931-2014. (https://nccsir.unc.edu/files/2013/10/Annual-Football-2014Fatalities-Final.pdf) [Accessed August 24, 2016]

28. Obrist WD, Langfitt TW, Jaggi JL, Cruz J, Gennarelli TA: Cerebral blood flow and metabolism in comatose patients with acute head injury. Relationship to intracranial hypertension. J Neurosurg 61:241-253, 1984

29. Overgaard J, Tweed WA: Cerebral circulation after head injury. Part 1: Cerebral blood flow and its regulation after closed head injury with emphasis on clinical correlations. J Neurosurg 41:531-541, 1974

30. Overgaard J, Tweed WA: Cerebral circulation after head injury. Part 2: The effects of traumatic brain edema. J Neurosurg 45:292-300, 1976

31. Post A, Hoshizaki TB, Gilchrist MD, Brien S, Cusimano M, Marshall S: Traumatic brain injuries: the influence of the direction of impact. Neurosurgery 76:81-91, 2015

32. Reulen HJ, Graham R, Spatz M, Klatzo I: Role of pressure gradients and bulk flow in dynamics of vasogenic brain edema. J Neurosurg 46:24-35, 1977

33. Saunders ML, Miller JD, Stablein D, Allen G: The effects of graded experimental trauma on cerebral blood flow and responsiveness to CO2. J Neurosurg 51:18-26, 1979

34. Smith DW, Bailes JE, Fisher JA, Robles J, Turner RC, Mills JD: Internal jugular vein compression mitigates traumatic axonal injury in a rat model by reducing the intracranial slosh effect. Neurosurgery 70:740-746, 2012

35. Strebel S, Lam AM, Matta BF, Newell DW: Impaired cerebral autoregulation after mild brain injury. Surg Neurol 47:128-131, 1997

36. Turner RC, Naser ZJ, Bailes JE, Smith DW, Fisher JA, Rosen CL: Effect of slosh mitigation on histologic markers of traumatic brain injury: laboratory investigation. J Neurosurg 117:1110-1118, 2012

37. Wong RH, Wong AK, Bailes JE: Frequency, magnitude, and distribution of head impacts in Pop Warner football: the cumulative burden. Clin Neurol Neurosurg 118:1-4, 2014

\section{Disclosures}

The authors report no conflict of interest. 